\title{
MICHEL BIDEAUX, Européens en voyage (1500-1800). Une anthologie
}

\section{Michele Mastroianni}

\section{OpenEdition}

\section{Journals}

\section{Edizione digitale}

URL: http://journals.openedition.org/studifrancesi/16296

DOI: 10.4000/studifrancesi. 16296

ISSN: 2427-5856

\section{Editore}

Rosenberg \& Sellier

\section{Edizione cartacea}

Data di pubblicazione: 1 juillet 2019

Paginazione: 150

ISSN: 0039-2944

\section{Notizia bibliografica digitale}

Michele Mastroianni, «MICHel BIDEAux, Européens en voyage (1500-1800). Une anthologie», Studi Francesi

[Online], 187 (LXIII | I) | 2019, online dal 01 juin 2019, consultato il 25 janvier 2021. URL: http://

journals.openedition.org/studifrancesi/16296 ; DOI: https://doi.org/10.4000/studifrancesi.16296

Questo documento è stato generato automaticamente il 25 janvier 2021.

\section{(9) $\odot \Theta \Theta$}

Studi Francesi è distribuita con Licenza Creative Commons Attribuzione - Non commerciale - Non opere derivate 4.0 Internazionale. 


\title{
MICHEL BIDEAUX, Européens en voyage (1500-1800). Une anthologie
}

\author{
Michele Mastroianni
}

\section{NOTIZIA}

MICHEL BIDEAUX, Européens en voyage (1500-1800). Une anthologie, Paris, Presses de l'Université Paris-Sorbonne, 2012, 782 pp.

1 Anche se uscita alcuni anni fa merita di certo una segnalazione questa antologia di testi sul viaggio in Europa, antologia che raccoglie sapientemente e per tipologia estratti interessanti di scritti su avventure ed esperienze di viaggio appunto che fanno della scoperta e della conoscenza diretta il tramite per dar vita a un genere letterario che affonda le sue radici nel Rinascimento per, come noto, svilupparsi nei secoli successivi. Pur rimandando il lettore alle scelte che concernono specificamente il Cinquecento, riteniamo opportuno menzionare i fitti capitoli su cui è costruita questa silloge di testi, attraverso la quale il curatore, Michel Bideaux, ha inteso delineare una prospettiva culturale precisa, cioè quella che privilegia lo sguardo del viaggiatore, attratto dal desiderio di un'esperienza consumata nell'immediato. Viaggiatore e viaggiatori europei spinti principalmente da un sentimento di curiositas che non è solo foriero di scoperta, quindi di nuova conoscenza, ma che si delinea anche come tensione all'acquisizione di un sapere espresso da tradizioni autoctone come quella del cibo, dei vestiti, dei sapori e degli odori, come pure degli spettacoli, degli usi e costumi in genere delle civiltà cui di volta in volta lo scrittore/viaggiatore si confronta.

2 Il volume che non si sviluppa su un discorso cronologico diacronico ma su aree geografiche e scelte tematiche che pongono a confronto sotto lo sguardo del lettore una varietà di testi che gravitano intorno a un interesse comune, comprende diciotto amplissimi capitoli (Le discours sur le voyage, pp. 17-100; L'Italie, pp. 101-144; La France, pp. 144-188; La Grande-Bretagne, pp. 189-228; La péninsule ibérique, pp. 229-262; L'Europe centrale, terre d'Empire, pp. 263-334; Aux marges orientales et nordiques, pp. 335-370; La 
Turquie et l'Empire ottoman, pp. 371-424; Afrique: le continent noir, pp. 425-472; L'Inde, pp. 473-490; La Sibérie, pp.491-506; L'Extrême orient, pp. 507-564; L’Arctique, pp. 565-574; Amérique du Nord Franco-Anglaise, pp.575-604; Les Antilles, pp. 605-616; L'Amérique ibérique, pp. 617-640; L'Océanie, pp. 641-686) che spaziano da argomentazioni incentrate sul perché viaggiare e sul come viaggiare a questioni antropologiche come la circoncisione degli ebrei di cui parla Montaigne, a considerazioni estetiche sui giardini dei Medici a Pratolino, al cannibalismo dei brasiliani, al pasto di Enrico IV, all'immensità del Pacifico.

3 Chiudono questa utilissima antologia un indice delle illustrazioni, una bibliografia selettiva, un indice dei nomi e dei luoghi e una sezione di notizie bio-bibliografiche degli autori che offre materiale interessante per il lettore appassionato di letteratura di viaggio come per lo specialista di settore. 